\begin{tabular}{c} 
journal homepage: http://ijiemjournal. uns.ac.rs/ \\
International Journal of Industrial \\
Engineering and Management \\
Volume $13 /$ No $1 /$ March $2022 / 58-75$ \\
\hline
\end{tabular}

Original research article

\title{
Joint optimization of product configuration and process planning in Reconfigurable Manufacturing Systems
}

\author{
R. C. Sabionia , J. Daaboula* and J. Le Duigou ${ }^{\mathrm{a}}$ \\ a Université de technologie de Compiègne, Roberval (Mechanics energy and electricity), Centre de recherche \\ Royallieu - CS 60319 - 60203 Compiègne Cedex, France
}

\section{A B STRACT}

A key factor for the successful implementation of mass customization is joint product-process optimization. This paper proposes a linear programming model that jointly optimizes product configuration and process planning in a reconfigurable manufacturing system (RMS) to minimize manufacturing costs while ensuring individual customer requirements (CR) satisfaction. The impact of the initial RMS configuration and changes in CRs on the total cost is investigated. The results show that for a given set of CR, different product variants can appear like the optimal solution, and the total cost can vary up to $30 \%$, confirming the benefits of joint product-process optimization.

\section{ARTICLE INFO}

Article history:

Received September 5, 2021

Revised January 14, 2022

Accepted January 18, 2022

Published online February 9, 2022

Keywords:

Mass customization;

Reconfigurable manufacturing systems;

Modular product design;

Product configuration;

Process planning

* Corresponding author:

Joanna Daaboul

joanna.daaboul@utc.fr

\section{Introduction}

Mass customization (MC) is a production strategy for producing a large variety of customized goods and services capable of meeting individual customer requirements at relatively low costs while keeping mass production efficiency [1]-[4].

Modular Product Design (MPD) is characterized by products composed of many building blocks that can be combined to create different product variants. MPD is well-known as the best strategy to manage high variety for MC [5], [6]. In MPD, multiple product variants can derive from a generic product archi- tecture through the combination of different module instances at the product configuration phase.

There are two main ways of offering mass-customizable products: 1) alternative-based, where customers configure their products from a set of product parts alternatives and 2,) attribute-based where customers are asked about their product attribute/functionalities preferences, based on which, a product is configured, by the seller, through the combination of candidate product modules.

The attribute-based approach reduces perceived complexity and increases customer satisfaction [7]. Customers prefer not to choose from a long list of 
customizable options but instead express their personal needs [8]. In this case, the company should be able to identify, among all product candidates, the one that satisfies all customer requirements at minimal cost, which is affected by raw material costs of modules and operational decisions related to the manufacturing process.

Defining product configuration and process decisions concurrently is a key issue in customer and manufacturer relationships, becoming a crucial factor of successful MC implementation [9], [10]. A product designed with no consideration of process constraints may increase costs and lead time, directly impacting customer satisfaction.

The shorter time to market and the increasing competitiveness and customer demand for variety have forced companies to increase their manufacturing systems' responsiveness and cost-effectiveness. From that arises the Reconfigurable Manufacturing Systems (RMS), which is known as the best manufacturing system to thrive in unpredictable and changeable markets [11].

The high RMS responsiveness is due to their ability to rapidly adjust their production capacity and functionality, within a product family, thanks to their machines' reconfigurability [11]. In RMS, many machine configurations can perform a single operation, while a single machine configuration can fulfill different operations. Thus, a given product can have many alternative process plans. Depending on the current RMS configuration, a specific process plan will lead to lower manufacturing costs. Hence, the process plan of a given product in RMS should often be revisited, highlighting the relevance of jointly optimizing product and process planning in RMS.

Some works have suggested that optimizing modular products and RMS decisions concurrently can be more advantageous and effective than sequential/ non-jointly methods [12], [13]. However, most of the works optimizing the process planning in RMS address a pre-defined product, with no consideration of the product configuration phase, meaning that they use a sequential (or non-jointly) approach [14]-[17]. Therefore, more research on this topic is still needed, including the development of new mathematical models and solution techniques. Further, research investigating to which extent the parameter modifications will affect the optimal solution in joint optimization is still missing (e.g., initial machines' configurations, functions required by the customer).

Therefore, the main research questions addressed in this paper are summarized as follows:
I) How to jointly optimize the product configuration, driven by individual customer requirements, with its process planning in an RMS to minimize the overall manufacturing cost?

II) How the initial RMS configuration can affect the overall manufacturing cost and the selected product variant to meet the same set of functions?

This paper proposes a $0-1$ integer linear programming (0-1 ILP) model, based on an attribute-based approach, to jointly optimize product configuration with process planning in RMS while ensuring all individual customer requirements are satisfied. A hybrid solution approach based on the combination of an exhaustive search method with CPLEX is developed to test and validate the proposed mathematical model. An analysis is carried out to investigate how changes in the current RMS configuration and customer requirements affect the overall manufacturing costs.

This paper is organized as follows. Section 2 brings the theoretical background. Section 3 presents the methodology followed by the problem statement in Section 4. The mathematical model and solution approach are presented in Section 5. Section 6 presents the mathematical model verification and validation as well as the results and analysis. Finally, Section 7 presents the conclusion.

\section{Theoretical background}

Concurrent product-process-supply chain engineering standout as one of the main MC enablers [18], [19]. These three issues are interdependent, but when companies provide high variety and mass-customized products, their interdependencies become higher and should be considered in an integrated manner [20].

In this paper, only the concurrent configuration of product and process is addressed, because related works have highlighted it as a key issue in MC development and customer/supplier relationship [9], [10]. Further, this paper addresses a specific type of modular process, the RMS, and the complexity related to its reconfiguration. Differing from a non-reconfigurable process, an RMS can be reconfigured at software and hardware levels to adjust its production capacity and functionality according to new market requirements [21]. Therefore, the process planning of a given product may change according to the RMS 
current configuration and may be revisited many times during its lifecycle.

Configuring products according to customer requirements is not recent as a research subject and has been broadly investigated in the literature. However, when it comes to the concurrent configuration of product and RMS, the number of researches is still very scarce, especially when individual customer requirements are considered in $\mathrm{MC}$ contexts.

Due to the lack of researches focused on the joint configuration of product and process planning in RMS for MC, this literature review is divided into two main parts. The first one presents an overview of researches working on concurrent product-process configuration for MC. In the second part, we bring a literature review focused on works addressing the concurrent optimization of product and RMS configuration.

\subsection{Joint Product-Process configuration for Mass Customization}

Works configuring products according to specific customer requirements for $\mathrm{MC}$ often embed the process costs into the module instance [22]-[25]. Although they consider customer requirements, these works do not directly address process decisions (i.e., process/production planning, scheduling, etc.) because they assume that each module/component has a fixed cost with no reference to process changes.

Customer requirements are often integrated into modular product configuration (module selection) optimization in assemble-to-order environments [26]-[28]. These works are generally focused on selecting the supplier of components/subassemblies that will lead to minimal cost while respecting customer's deadline and requirements. Similarly, Rezaei [29] and Galankashi [30] addressed the optimization of supplier selection and production planning, but in addition to cost and lead time, they also optimized the quality through the minimization of defective supplied components, which directly affects customer satisfaction.

Some works classify customer requirements into non-negotiable and negotiable requirements [9], [10], [31]. They mapped their problem into a two steps constraint satisfaction problem. At first, they filtered the solution space with non-negotiable elements, and second, optimized process planning integrated to product configuration according to negotiable requirements.

Customer requirements are also often addressed as functions/functional requirements that are mapped into modules or module instances [23], [25], [32][36]. These works consider that each customer requirement corresponds to a function associated with a given module, meaning that if this module appears in the final product, then the function/customer requirement is satisfied.

In summary, works optimizing the product configuration to meet specific customer requirements use them to constrain their optimization problem to ensure they will be satisfied in the configured product. Some papers addressed product and process configuration decisions jointly in other systems than RMS, backing up the relevance of integrating product and process decisions. Due to RMS reconfigurability and flexibility, it becomes still more relevant to integrate both decisions.

\subsection{Joint Product-Process configuration in RMS}

As previously stated, there are still relatively few works addressing the concurrent optimization of product decisions (e.g., design, configuration, family formation, etc.) and process planning (or assembly planning) in reconfigurable manufacturing (or assembly) systems.

Since RMS are built around product families, many researchers have investigated the optimization of product family formation/design or evolution considering RMS reconfiguration issues. Benderbal and Benyoucef [37], for example, tried to reduce the evolution effort within the same product family to introduce new products for meeting the evolutions in customer requirements. Abdi and Labib [38] investigated the impact of the product life cycle of different product families on the RMS's capacity usage. They addressed the impact of the customer needs changes on the product life cycle, based on market demands forecasting.

Although the previous works address strategies to integrate product and process decisions in RMS, their approaches are not based on product module selection or product configuration. Differing from them, Bryan et al. [12], [39] addressed the joint formation/evolution of product family and reconfigurable assembly lines (RAL), by considering a module selection approach, to optimize the total profit.

In addition, Bryan et al. [12] compared the joint optimization of a product family and RAL with the sequential (separated or non-joint) method. While in the joint optimization product and process decisions are taken concurrently, in the separated method, the product family is formed, and then, the assembly line 
is designed. Their analysis has shown that jointly optimizing product and RAS leads to equal or better profits than the sequential engineer strategy, where product family is formed and then the RAS is configured.

Some works from the literature have reported the joint optimization of product configuration and RMS or RAL. Pattanaik and Jena [40], for example, addressed the selection of modular products to be assembled into an RAL. They reported the selection of modules and their assembly sequence to minimize balance delay, cycle time, and smoothness index in MC contexts. However, they do not address individual customer requirements. Sabioni et al. [13], [41] focused on meeting individual customer requirements for $\mathrm{MC}$ while jointly optimizing product configuration, process planning, and layout design in RMS. They highlighted the benefits of concurrently optimizing product and process decisions in RMS.

Xu and Liang [42], [43] did not focus on MC, but they also tried to integrate modular products and assembly line configuration to optimize some performance criteria (e.g., product weight, reconfiguration cost, reliability, etc.). Yigit et al. [44] and Yigit and Allahverdi [45] concurrently optimized modular product configuration with an RMS configuration to meet individual/specific customer requirements. They stated many candidate sets of parameters representing different customer requirements to constrain product configuration optimization depending on customer demands. The total system reconfiguration cost was associated with the module instances selected to be manufactured without specifying which machines or workstations were reconfigured.

Mittal et al. [46] used multi-criteria decision analysis to choose a product variant according to the production process in an RMS. Based on the instances/ options of modules present in each product variant, they tried to select the one leading to maximum reliability and power at minimal reconfiguration cost. They assumed that reconfiguration cost was dependent on the reconfiguration effort. The latter is associated with the costs of adding/removing modules from machines. They do not address individual customer requirements or MC.

In summary, concurrent optimization of product module selection and RMS/RAL configuration has been reported as more advantageous than the sequential optimization strategy [12]. However, no previous work has investigated the impact of different initial machine configurations while jointly optimizing process planning and product configuration according to different customer requirements. In this work, we investigate how the changes in initial machine configuration and customer requirements affect total manufacturing cost in RMS while jointly optimizing product configuration and process planning in RMS for MC.

\section{Methodology}

The methodology used to develop this research can be described into five main steps, which are illustrated in Figure 1. In the first one, the research scope was defined through the problem statement, which is detailed in Section 4. Once the problem was defined and objectives specified, a mathematical model was developed to quantitatively describe the problem stated in Section 4. The mathematical model as well as all assumptions that delimit the scope and limits of the model are detailed in Section 5.1. A solution approach was developed to solve and verify the mathematical problem, as presented in Section 5.2.

Following, the mathematical model and the solution approach were verified through an illustrative example, presented in Section 6. It is important to highlight, that the mathematical model and solution approach were tested for different inputs (e.g., input cost and time values, functions required, etc.) and different problems sizes; however, in this paper, only one illustrative example is presented. After validating the mathematical consistency and the solution approach's ability to solve it, we carried out an analysis to evaluate the impact of changing machines' initial configuration (Section 6).

\section{Problem statement}

This paper addresses the attribute-based customization problem to jointly optimize the product configuration according to customer requirements and the process planning in an RMS.

Customer requirements can be described in terms of product functions (PF), which can be satisfied by at least one available module instance (MI). Each MI can satisfy one or many PFs. A set of MIs forms a product variant. Therefore, all product variants compounded of MIs, which together satisfy all required PFs, correspond to products meeting all customer requirements, and therefore, are solution candidates.

Each product candidate requires a set of operations to be manufactured. Depending on the product 


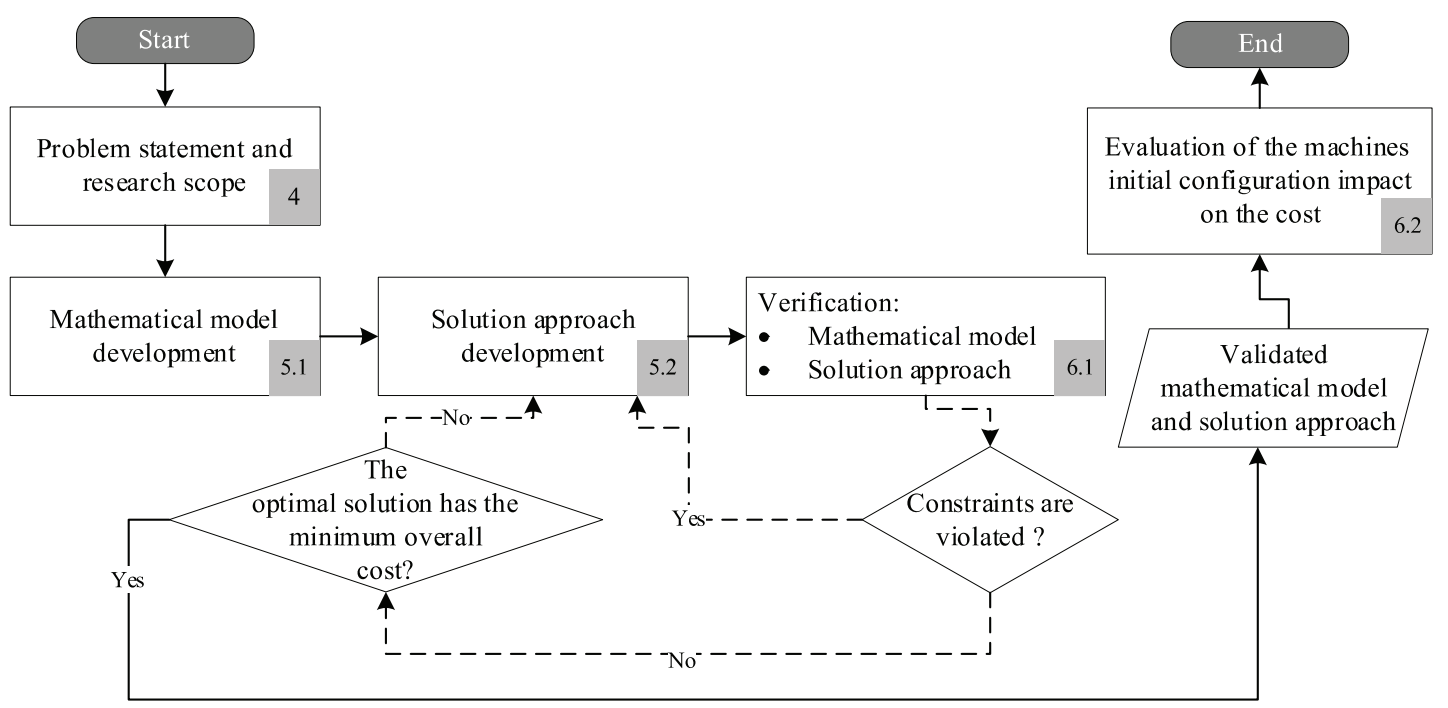

Figure 1. Methodology illustration. The number appearing in each bloc corresponds to the section in which the methodology step is detailed

candidate selected, a given set of operations should be processed. The process planning is responsible for assigning those operations to specific machine configurations. Each machine can have multiple configurations, and each of them can perform one or many operations. A given operation can be performed by different machine configurations.

Therefore, the problem statement can be summarized as follows:

The joint optimization of product configuration and process planning in RMS consists of simultaneously finding the product configuration - that satisfies all customer requirements - and its corresponding process plan resulting in minimal manufacturing cost.

\section{Proposition}

\subsection{Mathematical model}

This section presents the 0-1 ILP model developed to concurrently optimize modular product configuration and process planning in an RMS, driven by individual customer requirements. Its objective is minimizing overall manufacturing costs, including costs of (1) module instances' raw material (CRM), (2) manufacturing and assembly operations (COP), (3) machine configuration change (CCC), and (4) material-handling (MHC).

Before detailing the mathematical model, we would like to explain how the attribute-based customization process is addressed by the mathematical model proposed in this paper. First of all, this mathematical model assumes that the customer can choose, within all available PFs which ones she/he desires in her/his product (Figure 2). Each PF can be satisfied by at least one available MI, meaning that several product variants can be created from the combination of different MIs capable of satisfying the set of PFs. Therefore, there are probably many product variants candidate solutions for the set of PFs required by the customer. Once the customer selected the desired PFs, the latter will constraint the solution space. The solution space of product configuration comprises all feasible combinations of MIs, each representing a different product variant, according to their compatibility constraints.

MIs belonging to each product variant require specific processing operations to be fabricated and assembled, which are supposed to be sequenced and assigned to different machine configurations while ensuring minimal processing cost. Therefore, each product variant candidate requires a given process plan configuration in an RMS. It is assumed that each machine can assume multiple configurations and perform different operations, while different machine configurations can perform the same operation. The optimal solution will correspond to the product configuration (product variant) and the process planning that together led to the minimal overall manufacturing cost, including all costs previously mentioned.

In summary, the major decisions related to the integrated optimization of the product's and RMS's configuration are described as follows:

I. Decisions on product configuration: a. Module instances selection: define which module instances will compose the product variant, ensuring that all FRs are satisfied.

b. Operations identification: identify which operations will be manufactured based on the module instances selected. 


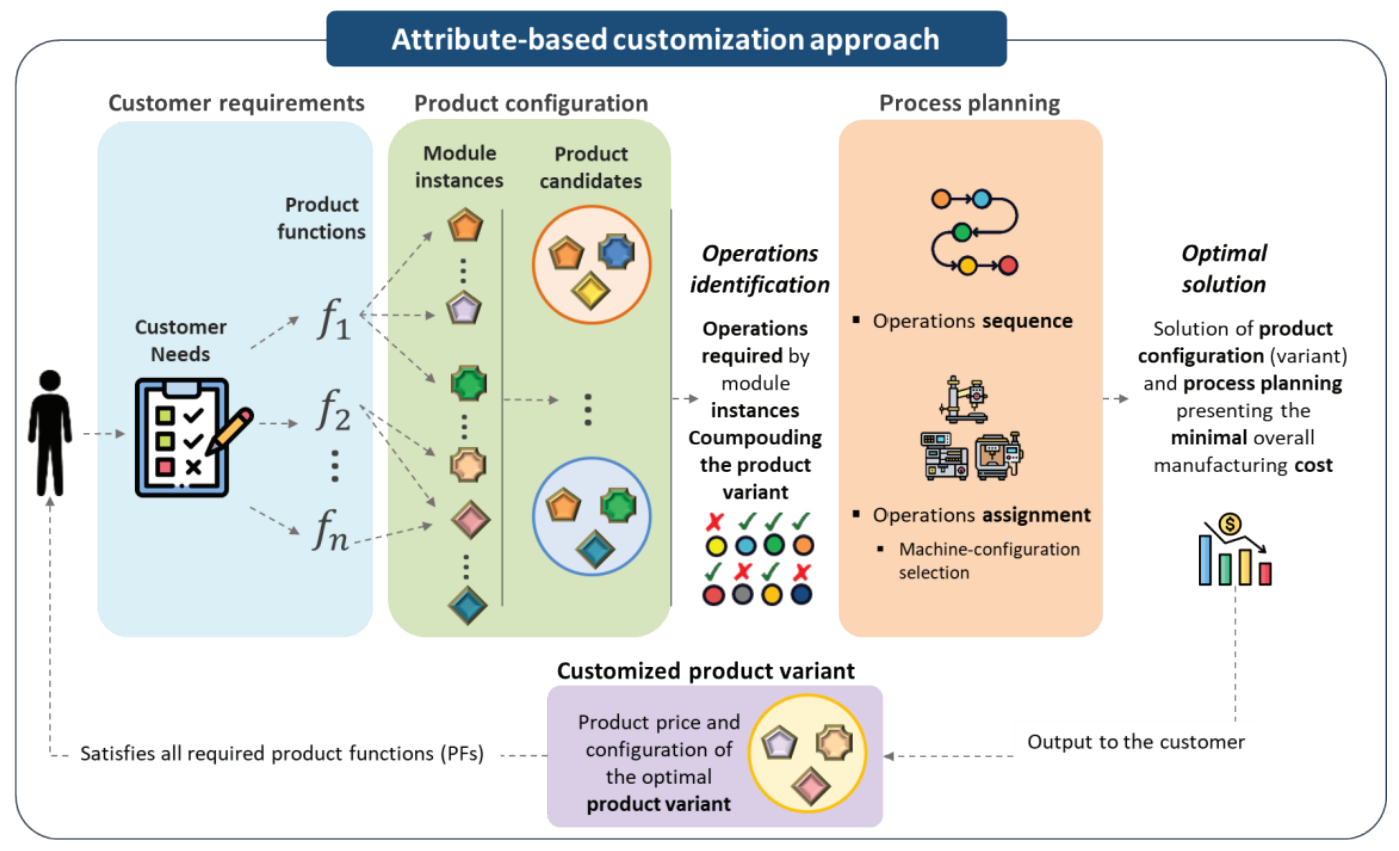

Figure 2. Illustration of the joint optimization of product configuration and process planning in RMS for MC

II. Decisions on RMS configuration selection:

a. Process planning: sequence and assign identified operations to the machine-configurations while respecting precedence and compatibility constraints and considering current machine configuration.

Here below we present the main assumptions used on the mathematical model development according to the research scope.

I. Each product function (PF), can be satisfied by at least one module instance;

II. Module instances are independent; the selection of an instance from module $\mathrm{m}$ does not imply the inclusion of another instance from module $m$ '.

III. Modules have decoupled interfaces;

IV. The raw material for producing module instances are prompt available;

V. Cost and time of changing an RMT configuration include both hardware and software levels;

VI. Each machine can be configured in a set of available configurations;

VII. Each machine configuration can perform one or more operations;

VIII.All machines are available and compatible;

IX. Each operation can be performed by one or several pairs of machine-configuration.

The notations used on the mathematical model are described below:

$\begin{array}{cl}f & \text { Index of all available PFs } \\ m, m^{\prime} & \text { Module index } \\ i, i^{\prime} & \text { Module instance index } \\ p, p^{\prime} & \text { Operations index } \\ w, w^{\prime} & \text { Machine index } \\ c, c^{\prime} & \text { Machine configuration index } \\ j & \text { Index of process plan position }\end{array}$

Some input parameters are required to find the optimal solution. They can be divided into three main issues: I) Product and PFs, II) Product processing and III) Process planning. Each will be further detailed in the following.

I. Product and PFs: the set of modules/module instances available to fulfill the available functions in the product are provided by the product design team. No module instance can be created in this step.

\begin{tabular}{|c|c|}
\hline Parameter & Description \\
\hline$F$ & $=\{1,2, \ldots, f, \ldots,|F|\}, \begin{array}{l}\text { Set of all available product } \\
\text { functions }(P F S)\end{array}$ \\
\hline$D_{f}$ & $\left\{\begin{array}{l}=1, \text { if } f \text { is required } \\
=0 \text { otherwise }\end{array}\right.$ \\
\hline$M$ & $=\{1,2, \ldots, m, \ldots,|M|\}$, Set of available modules \\
\hline$I$ & $=\{1,2, \ldots, i, \ldots,|I|\}$, Set of available module instances \\
\hline$G_{m, i, m^{\prime}, i^{\prime}}$ & $\left\{\begin{array}{c}=1, \text { if instance } i \text { of module } m \text { is compatible with } \\
\text { instance } i^{\prime} \text { of module } m^{\prime}\end{array}\right.$ \\
\hline & $=0$, otherwise \\
\hline$S_{m i f}$ & $\left\{\begin{array}{l}=1, \\
\text { if instance } i \text { of module } m \text { satisfies the } \\
\text { function } f\end{array}\right.$ \\
\hline & $=0$, otherwise \\
\hline
\end{tabular}


II. Product processing: the information regarding the operations required by each product module instance and the precedence relation between these operations are known.

\begin{aligned} & Parameter Description \\ & \hline$O P \quad=\{1,2, \ldots, p, \ldots,|O P|\}$, Set of available operations \\ &$R_{p m i} \quad\left\{\begin{array}{c}=1, \text { if } \text { instance } \text { i of module } m \text { requires } \\ \text { an operation } p \text { to be manufactured } \\ =0, \text { otherwise }\end{array}\right. \\ & P_{p p^{\prime}} \quad\left\{\begin{array}{c}=1, \text { if an operation } p \text { must be processed before } \\ \text { an operation } p^{\prime} \\ \forall p, p^{\prime} \in O P, \quad p \neq p^{\prime}\end{array}\right.\end{aligned}$

III. Process planning: the machine-configurations cost and time required to accomplish each operation $\mathrm{p}$ is supposed to be available. The cost and time of changing machines' configuration and handling material are also available. Machines are placed into layout lo cations that have known distances between them.

\begin{tabular}{|c|c|}
\hline Parameter & Description \\
\hline$W$ & $=\{1,2, \ldots, w, \ldots,|W|\}, \begin{array}{l}\text { Set of all available } \\
\text { machines }\end{array}$ \\
\hline$C_{w}$ & $\begin{array}{r}=\left\{1,2, \ldots, c, \ldots,\left|C_{w}\right|\right\}, \begin{array}{l}\text { Set of available } \\
\text { configurations for machine } w\end{array}\end{array}$ \\
\hline$c_{w}^{0}$ & $\begin{array}{l}\text { Initial configuration } c^{0} \text { of machine } w \text {, where } \\
c_{w}^{0} \in C_{w}\end{array}$ \\
\hline$Q_{p w c}$ & $\left\{\begin{array}{c}=1, \text { if an operation } p \text { is feasible on machine } w \\
\quad \text { with configuration } c \\
=0, \text { otherwise }\end{array}\right.$ \\
\hline$J$ & $\begin{array}{c}=\{1,2, \ldots, j, \ldots,|J|\}, \begin{array}{l}\text { Set of all process plan } \\
\text { positions }\end{array} \\
\end{array}$ \\
\hline$d_{w w}$ & Distance between each pair ( $w$ and $w^{\prime}$ ) of machines \\
\hline$C R_{m i}$ & Raw material cost of an instance $i$ of module $m$ \\
\hline$C O_{p w c}$ & $\begin{array}{l}\text { Cost of operation p processed on machine } w \text { with } \\
\text { configuration c per time unit }\end{array}$ \\
\hline$C C_{w, c c^{\prime}}$ & $\begin{array}{l}\text { Cost of machine } w \text { changing from configuration } c \\
\text { to } c^{\prime} \text { per time unit }\end{array}$ \\
\hline$C T$ & Cost of transporting material per distance unit \\
\hline$T O_{p w c}$ & $\begin{array}{l}\text { Time of processing operation } p \text { on machine } w \text { with } \\
\text { configuration } c\end{array}$ \\
\hline$T C_{w, c c \prime}$ & $\begin{array}{l}\text { Time of machine } w \text { changing from configuration } \\
\text { c to } c^{\prime}\end{array}$ \\
\hline
\end{tabular}

Decision variables:

$$
\begin{aligned}
& y_{m i}\left\{\begin{array}{l}
=1, \text { if } \text { instance } i \text { of module } m \text { is selected } \\
=0, \text { otherwise }
\end{array}\right. \\
& x_{p w c j} \quad\left\{\begin{array}{c}
=1, \text { if operation } p \text { is assigned to machine } w \text { with } \\
\text { configuration } c \text { in process plan position } j \\
=0, \text { otherwise }
\end{array}\right.
\end{aligned}
$$$$
u_{w, c, c^{\prime}, j, j+1}\left\{\begin{array}{r}
=1, \text { if there is a change of configuration c to } c^{\prime} \text { of machine } \\
\quad \begin{array}{r}
, \text { between position } j \text { and } j+1 \\
\text { in the process plan }
\end{array} \\
=0, \text { otherwise }
\end{array}\right.
$$

$$
\begin{aligned}
& h_{w c j} \quad\left\{\begin{array}{l}
=1, \text { if machine } w \text { with configuration } c \text { is in process plan } \\
=0, \text { otherwise } \quad \text { position } j
\end{array}\right. \\
& t_{w, w^{\prime} j, j+1}\left\{\begin{array}{c}
=1, \text { if machine } w \text { is utilized at position } j \text { and machine } \\
w^{\prime} \text { is utilized at position } j+1 \text { in the process plan } \\
=0, \text { otherwise }
\end{array}\right.
\end{aligned}
$$

Objective function:

The objective function presented in Eq. (1) aims to minimize the overall manufacturing cost, including costs of raw material, operations, machine configuration change, and material handling.

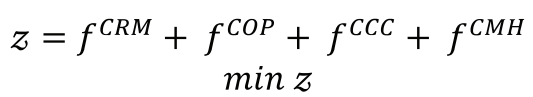

Where:

$f^{C R M}$ : Cost of raw material of module instances:

$\sum_{m} \sum_{i} y_{m i} \times C R_{m i}$

$f^{C O P}$ : Cost of operations (manufacturing and assembly) carried out each in a given machine-configuration pair:

$$
\sum_{j} \sum_{p} \sum_{w} \sum_{c} x_{p w c j} \times C O_{p w c} \times T O_{p w c}
$$

$f^{C C C}$ : Cost of changing the configuration of machines:

$$
\sum_{w} \sum_{c, c \prime \in C_{w}} \sum_{j} u_{w, c c^{\prime}, j j+1} \times C C_{w, c c^{\prime}} \times T C_{w, c c^{\prime}}
$$

$f^{C M H}$ : Costs of material handling between all pairs of machines:

$$
\sum_{w, w^{\prime} \in W} \sum_{j} t_{w w^{\prime} j, j+1} \times C T \times d_{w, w \prime}
$$

\section{Subject to:}

The following constraints are related to product configuration. Eq.(6) states that only one instance i of module $\mathrm{m}$ can be selected from alternative instances of the same module at a time. Eq.(7) ensures that only compatible module instances will be present in the same product variant. Eq.(8) ensures that each required $\mathrm{PF}$ must be satisfied by at least one selected module instance at a time.

$$
\begin{aligned}
& \sum_{i} y_{m i} \leq 1 \quad \forall m \in M \\
& y_{m i}+y_{m{ }^{\prime}{ }^{\prime}} \leq G_{m, i, m^{\prime}, i^{\prime}}+1 \quad \forall m, m^{\prime} \in M \\
& \forall i, i^{\prime} \in I
\end{aligned}
$$


$\sum_{m} \sum_{i} y_{m i} \times S_{m i f} \geq D_{f}$

$\forall f \in F$

(8)

The following equations present operations-related constraints. Eq.(9) states that each operation is processed at most at one process plan position by one machine-configuration. Eq. (10) states that each operation is processed at most once in one machineconfiguration. With constraints, Eq.(9) and (10), Eq. (11) ensures that only required operations will be processed, and they must each be performed in only one machine-configuration in only one process plan position. Eq. (12) states that an operation can only run in a machine having the correct configuration. Eq. (13) states operations' precedence relationships.

$\sum_{p} \sum_{w} \sum_{c} x_{p w c j} \leq 1$

$\forall j \in J$

$\sum_{w} \sum_{c} \sum_{j} x_{p w c j} \leq 1 \quad \forall p \in O P$

$\sum_{p} \sum_{m} \sum_{i} y_{m i} \times R_{p m i}=\sum_{p} \sum_{w} \sum_{c} \sum_{j} x_{p w c j} \times Q_{p w c}$

$$
\begin{gathered}
\forall w \in W \\
x_{p w c j} \leq h_{w c j} \quad \forall j \in J \\
\forall c \in C \\
\forall p \in O P
\end{gathered}
$$

$$
\begin{aligned}
& \sum_{w^{\prime}} \sum_{j^{\prime}=1}^{j-1} x_{p^{\prime} w^{\prime} c^{\prime} j^{\prime}} \geq \sum_{w} \sum_{c} x_{p, w, c, j} \times P_{p \prime p} \\
& \forall p, p^{\prime} \in O P \\
& p \neq p^{\prime} \\
& \forall j=1,2, \ldots, n
\end{aligned}
$$

The following equations concern the constraints mainly associated with machine changes. Eq. (14) ensures that there is at most one configuration change for a machine w between position j-1 and j. Eq. (15) ensures that there is at most one machine change between position j-1 and j. Eq. (16) states if there is a machine change between position $\mathrm{j}-1$ and $\mathrm{j}$, while Eq. (17) states if there is a configuration change for a given machine $\mathrm{w}$ between position j-1 and j. Eq.(18) states that each machine has exactly one configuration at each process plan position. Eq. (19) ensures that a machine's configuration stays the same unless its configuration is changed in the process plan. Eq. (20) sets the initial configuration of each machine.

$$
\begin{aligned}
& \sum_{c, c^{\prime} \in C_{W}} u_{w, c, c^{\prime} j, j+1} \leq 1 \quad \forall j \in J \\
& \sum_{w, w^{\prime} \in W} t_{w, w^{\prime} j, j+1} \leq 1 \quad \forall j \in J \\
& t_{w, w^{\prime} j, j+1} \geq \sum_{c}\left(x_{p w c j}+x_{p^{\prime} w^{\prime} c j+1}\right)-1 \quad \begin{array}{c}
\forall j \in J \\
\forall p, p^{\prime} \in O P \\
\forall w, w^{\prime} \in W \\
w \neq w^{\prime}
\end{array} \\
& \forall j \in J \\
& \begin{array}{c}
u_{w, c, c^{\prime} j, j+1} \geq x_{p w c j}+x_{p^{\prime} w c^{\prime}, j+1}-1 \quad \forall p, p^{\prime} \in O P \\
\forall w \in W \\
\forall c, c^{\prime} \in C_{w} \\
c \neq c^{\prime}
\end{array}
\end{aligned}
$$

$$
\sum_{c} h_{w c j}=1 \quad \begin{array}{r}
\forall w \\
\forall j \in W
\end{array}
$$$$
h_{w c j}=h_{w c j-1}
$$$$
\begin{array}{lr}
+\sum_{c^{\prime}} u_{w, c^{\prime}, c, j-1, j} & \forall w \in W \\
-\sum_{c^{\prime}} u_{w, c, c^{\prime} j-1, j} & \forall j \in J
\end{array}
$$

$$
\begin{aligned}
h_{w c j}=c_{w}^{0} & \forall w \in W \\
& \forall c \in C \\
& \forall j=0
\end{aligned}
$$

Eq.(21)-(25) represent the decision variables domains.

$$
\begin{array}{ll}
y_{m i} \in\{0,1\} & \forall m \in M \quad \forall i \in I(21) \\
x_{p w c j} \in\{0,1\} & \forall w \in W \quad \forall j \in J \\
& \forall p \in O P \quad \forall c \in C_{W}(22) \\
u_{j, j+1, w, c, c^{\prime}} \in\{0,1\} \quad \forall j \in J & \forall c, c^{\prime} \in C_{w} \quad \forall w \in W(23) \\
t_{w, w^{\prime} j, j+1} \in\{0,1\} & \forall j \in J \quad \forall w, w^{\prime} \in W(24) \\
h_{w c j} \in\{0,1\} & \forall w \in W \\
& \forall c \in C
\end{array}
$$

\subsection{Solution approach}

A deterministic approach is proposed to test and validate the mathematical model detailed in Section 5.1. This hybrid approach is based on the com- 
bination of an exhaustive search algorithm (ESA) (presented in Algorithm of Appendix A) and IBM CPLEX solver, as presented in Figure 3. The ESA is used in the first phase to filter all MIs combinations (i.e. product variants - PVs) capable of satisfying the set of PFs required by the customer while respecting module instances compatibility constraints.

The CPLEX, a commercial software based on the combination of branch and bound algorithm with cutting plane method [47], is used in the second phase to get the optimal process plans for each product variant candidate individually. The optimal solutions found for the product variants were ranked (i.e., process planning with the minimal cost), and then the global optimal solution corresponding to the minimal overall manufacturing cost - including costs of product variant (raw material costs) and process planning - was selected.

\section{Results and analysis}

\subsection{Illustrative example description}

An illustrative example is used to verify the mathematical model consistency and solution approachability to solve that. It contains 11 available product functions, 4 modules (total of 10 module instances), 16 operations, and 4 machines (a total of 14 machine configurations).

As shown in Table 1, one module instance can satisfy different PFs, and a given function can be satisfied by different MIs. Table 2 presents MIs compatibility. A product variant is formed only of compatible MIs. Therefore, their compatibility will directly affect the number of product variant candidates for a given set of functions required by the customer.

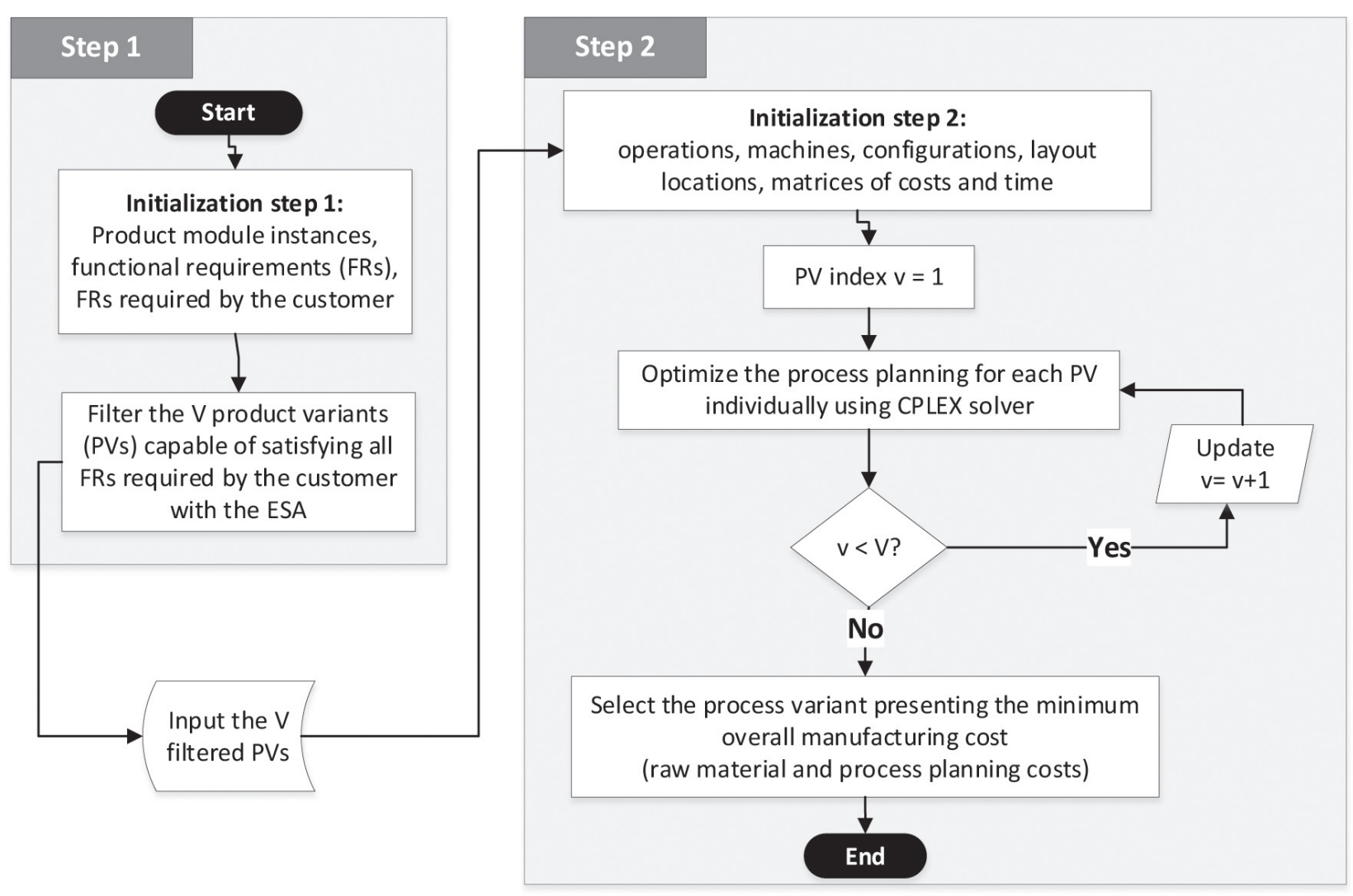

Figure 3. The framework of the hybrid method based on the exhaustive search algorithm and CPLEX (ESA-CPLEX) for solving the 0-1 ILP problem of jointly optimizing the product configuration and process planning in RMS.

Table 1. List of module instances and the product functions each of them satisfies. M12 represents module instance 2 of module 1

\begin{tabular}{l|ccc|cc|cc|ccc}
\hline Modules: & \multicolumn{3}{|c|}{ M1 } & \multicolumn{3}{|c|}{ M2 } & \multicolumn{3}{c|}{ M3 } & \multicolumn{3}{c}{ M4 } \\
\hline Cost: & 2 & 2 & 3,5 & 8,76 & 6,1 & 15,9 & 26,7 & 16 & 18,3 & 17,8 \\
Module instances: & M11 & M12 & M13 & M21 & M22 & M31 & M32 & M41 & M42 & M43 \\
Functions satisfied: & F1, F4 & F2, F4 & F3, F4 & F5, F6 & F6 & F8 & F7 & F9 & F9, F10 & F10, F11 \\
Required operations: & 1,2 & 1,3 & $1,2,4$ & $6,7,8$ & 5,7 & $9,10,12$ & $10,11,12$ & 14,16 & 14,16 & $13,15,16$ \\
\hline
\end{tabular}


Table 2. Module instances compatibility

\begin{tabular}{lcccccccccc}
\hline Instances & M11 & M12 & M13 & M21 & M22 & M31 & M32 & M41 & M42 & M43 \\
\hline M11 & 1 & 0 & 0 & 1 & 1 & 1 & 1 & 1 & 1 & 1 \\
M12 & 0 & 1 & 0 & 1 & 1 & 1 & 1 & 1 & 1 & 1 \\
M13 & 0 & 0 & 1 & 1 & 1 & 1 & 1 & 1 & 1 & 1 \\
M21 & 1 & 1 & 1 & 1 & 0 & 1 & 1 & 0 & 1 & 1 \\
M22 & 1 & 1 & 1 & 0 & 1 & 0 & 1 & 1 & 0 & 1 \\
M31 & 1 & 1 & 1 & 1 & 0 & 1 & 0 & 1 & 1 & 1 \\
M32 & 1 & 1 & 1 & 1 & 1 & 0 & 1 & 1 & 1 & 1 \\
M41 & 1 & 1 & 1 & 0 & 1 & 1 & 1 & 1 & 0 & 0 \\
M42 & 1 & 1 & 1 & 1 & 0 & 1 & 1 & 0 & 1 & 0 \\
M43 & 1 & 1 & 1 & 1 & 1 & 1 & 1 & 0 & 0 & 1 \\
\hline
\end{tabular}

Table 1 also shows the operations required by each module instance to be manufactured. Depending on the MIs forming a product variant, different operations should be manufactured, directly affecting process planning. The total raw material cost will be represented by the sum of all module instance costs present in a product. The cost of each module instance is also shown in Table 1. Further details are presented in Appendix B.

\subsection{Mathematical model and solution approach verification}

The mathematical model, as well as the solution approach, were implemented in Python 3.7 language. DOcplex Python API was used for modeling the mathematical programming problem as well as to import CPLEX solver. The calculations were carried out in a laptop computer powered by an Intel Core i7-7600U CPU(2.80 GHz) and $16 \mathrm{~GB}$ of RAM.

Table 3 summarizes some of the main inputs used to verify the 0-1 ILP model (W1C4 means configuration 4 of machine 1). The other inputs were previously presented in this section or detailed in Appendix B.

Table 3. Some of the main inputs used in the illustrative example

\begin{tabular}{cc}
\hline Required product functions & Initial machines' configurations \\
\hline $\mathrm{F}_{2}, \mathrm{~F}_{6}, \mathrm{~F}_{7}, \mathrm{~F}_{10}$ & $\mathrm{~W}_{1} \mathrm{C}_{4}, \mathrm{~W}_{2} \mathrm{C}_{2}, \mathrm{~W}_{3} \mathrm{C}_{2}, \mathrm{~W}_{4} \mathrm{C}_{5}$ \\
\hline
\end{tabular}

Table 4 summarizes the optimal solution found by ESA-CPLEX, evidencing that the best product variant is composed of the following module instances $M_{1} I_{2}, M_{2} I_{1}, M_{3} I_{2}, M_{4} I_{2}$. Only one MI of each module type was selected, all MIs are compatible (see Table 2 ), and all functions required were satisfied, which means that all constraints related to the product and functions were satisfied (see Eq. 6-8). The process plan shows that each operation was performed once by only one machine-configuration couple. Further, all operations required by the selected module instances were correctly performed, with respect to the precedence constraints. Therefore, constraints related to the operations processing (Eq. 9-13) were also satisfied.

The total cost of the product configuration and the process plan obtained as optimal solution corresponds exactly with the sum of costs associated with:

1. $f^{C R M}$ : Raw material costs of module instances selected in the optimal product configuration

2. $f^{C O P}$ : Costs of processing the required operations in the corresponding machine-configurations

3. $f^{C M H}$ : Costs of transferring material between machines (e.g. from machine $\mathrm{W}_{1}$ to machine $\mathbf{W}_{2}$ between process plan positions $\mathbf{J}_{4}$ and $\mathbf{J}_{5}$ )

4. $f^{C C C}$ : Costs of changing a machine configuration :

I) Between consecutive positions: e.g. from configuration $\mathrm{C}_{2}$ to $\mathrm{C}_{2}$ of machine $\mathrm{W}_{3}$ between process plan positions $\mathrm{J}_{7}$ and $\mathrm{J}_{8}$;

II) Between non-consecutive positions: e.g. from configuration $\mathrm{C}_{2}$ to $\mathrm{C}_{2}$ of machine $\mathrm{W}_{2}$ between process plan positions $\mathbf{J}_{2}$ and $\mathbf{J}_{5}$

Therefore, all constraints associated with the machine-configuration changes (Eq. 14-20) were also validated. Since the ESA-CPLEX is an exact approach, it is expected that it will always return the same result whenever the input set keeps the same, which was confirmed by the other two runs we have done. That same procedure was repeated for differ- 
Table 4. Optimal solution considering the inputs presented in Table 3

\begin{tabular}{cccccccccccc}
\hline $\begin{array}{c}\text { Product } \\
\text { configuration/variant }\end{array}$ & \multicolumn{3}{c}{ Total cost } & \multicolumn{3}{c}{ Computation time } \\
\hline $\mathrm{M}_{1} \mathrm{I}_{2}, \mathrm{M}_{2} \mathrm{I}_{1}, \mathrm{M}_{3} \mathrm{I}_{2}, \mathrm{M}_{4} \mathrm{I}_{2}$ & \multicolumn{3}{c}{$144.6 €$} & \multicolumn{5}{c}{$122,2 \mathrm{~s}$} \\
\hline $\begin{array}{c}\text { Process plan } \\
\text { position }\end{array}$ & $J_{1}$ & $J_{2}$ & $J_{3}$ & $J_{4}$ & $J_{5}$ & $J_{6}$ & $J_{7}$ & $J_{8}$ & $J_{9}$ & $J_{10}$ \\
\hline $\begin{array}{c}\text { Operation } \\
\text { Machine }\end{array}$ & $\mathrm{OP}_{1}$ & $\mathrm{OP}_{3}$ & $\mathrm{OP}_{6}$ & $\mathrm{OP} P_{8}$ & $O P_{7}$ & $O P_{10}$ & $O P_{14}$ & $O P_{11}$ & $O P_{16}$ & $O P_{12}$ \\
Configuration & $\mathrm{C}_{2}$ & $\mathrm{~W}_{2}$ & $\mathrm{~W}_{1}$ & $\mathrm{~W}_{1}$ & $\mathrm{~W}_{2}$ & $W_{2}$ & $W_{3}$ & $W_{3}$ & $W_{3}$ & $W_{3}$ \\
\hline & & $C_{4}$ & $C_{4}$ & $C_{1}$ & $C_{1}$ & $C_{2}$ & $C_{1}$ & $C_{1}$ & $C_{1}$ \\
\hline
\end{tabular}

ent examples (with different input values), in all of them the constraints were respected, and the optimal solution proposed was that with the minimum cost.

Based on the previous analyses, we could validate the mathematical model consistency regarding the problem stated in this research. Similarly, we could validate the solution approach's ability to solve the proposed mathematical model, confirming the applicability of the ESA-CPLEX to solve the joint optimization of the product-RMS configuration problem as described in Section 4.

\subsection{Evaluation of the initial machines' configurations changeovers}

In Section 6.2, we carried out some analyses to test and validated the mathematical model and solution approach considering the specific inputs from Table 3. Nevertheless, the example addressed represents only one possibility within the illustrative example. It means, the customer could require different PFs or even, the current RMS configuration (initial machines' configurations) could be not that presented in Table 3.

The inputs described in Table 3 are unpredictable and can vary according to the RMS current state and the customer needs. Therefore, this section aims to investigate how machines' initial configurations and a different set of required functions affect the optimization's results.

The use case (illustrative example) used here is the same introduced in Section 6.1. In this example, each machine has a different number of configurations $\left(\mathrm{W}_{1}=4, \mathrm{~W}_{2}=3, \mathrm{~W}_{3}=2\right.$, and $\left.\mathrm{W}_{4}=5\right)$. If all machines' configurations are combined there are 120 possible initial configurations (i.e., $4 \times 3 \times 2 \times 5=120$ ) . The initial machines' configurations were changed at a time while all other parameters were kept the same. Table 5 presents a list fragment of the 120 initial RMS configurations according to the machineconfigurations available that were tested in this work.

Three groups of functions were selected to represent three different sets of customer requirements (Table 6). Group 1 corresponds to functions $\mathbf{F}_{2}, \mathbf{F}_{6}$, $\mathrm{F}_{7}$, and $\mathrm{F}_{10}$, already introduced in the previous section. Group 2 is composed of the following functions $\mathbf{F}_{2}, \mathbf{F}_{6}$, $\mathrm{F}_{7}$, and $\mathrm{F}_{9}$, meaning that only one function changed compared to Group $1\left(\mathbf{F}_{10}\right.$ replaced by $\left.\mathbf{F}_{9}\right)$. Functions required in Group 3 correspond to $\mathrm{F}_{4}, \mathrm{~F}_{5}, \mathrm{~F}_{8}$, and $\mathrm{F}_{9}$ and then, they are all different from Group 1.

Table 6 summarizes the number of product candidates for each group of functions as well as the frequency these product variants appeared as an optimal solution within the 120 runs for each group. The product variants that most frequently appeared as an optimal solution (highlighted in grey) in each group

Table 5. Fragment of the list of all possible initial machines' configurations

\begin{tabular}{c|cccc|ccc|cc|ccccc}
\hline Machine & \multicolumn{5}{|c|}{ W1 } & \multicolumn{3}{c|}{ W2 } & \multicolumn{3}{c|}{ W3 } & \multicolumn{5}{c}{ W4 } \\
\hline Configuration & C1 & C2 & C3 & C4 & C1 & C2 & C3 & C1 & C2 & C1 & C2 & C3 & C4 & C5 \\
\hline Run 1 & 0 & 0 & 1 & 0 & 1 & 0 & 0 & 0 & 1 & 0 & 0 & 0 & 1 & 0 \\
Run 2 & 0 & 0 & 1 & 0 & 1 & 0 & 0 & 0 & 1 & 0 & 1 & 0 & 0 & 0 \\
Run 3 & 0 & 0 & 1 & 0 & 1 & 0 & 0 & 0 & 1 & 1 & 0 & 0 & 0 & 0 \\
&. &. &. &. &. &. &. &. &. &. &. &. &. &. \\
. &. &. &. &. &. &. &. &. &. &. &. &. &. &. \\
. &. &. &. &. &. &. &. &. &. &. &. &. &. &. \\
Run 118 & 0 & 1 & 0 & 0 & 0 & 0 & 1 & 1 & 0 & 1 & 0 & 0 & 0 & 0 \\
Run 119 & 0 & 1 & 0 & 0 & 0 & 0 & 1 & 1 & 0 & 0 & 0 & 0 & 0 & 1 \\
Run 120 & 0 & 1 & 0 & 0 & 0 & 0 & 1 & 1 & 0 & 0 & 0 & 1 & 0 & 0 \\
\hline
\end{tabular}


presented the cheaper raw material costs and the lower number of operations of the corresponding group.

The results in Table 6 suggest that product variants requiring the same number of operations as the product variant that appeared most frequently, but about $6 \%$ more expensive than the latter, will be the optimal solution of some RMS configurations, but in a lower frequency (see product variants $1 \mathrm{~A}$ and 1B). When the raw material cost of two product variants is the same, the product variant requiring one more operation will appear much less frequently. In the case of product variants $3 \mathrm{~A}$ and $3 \mathrm{~B}, 3 \mathrm{~A}$ appeared $87.5 \%$ while $3 \mathrm{~B}$ only $12.5 \%$. When the other product variants require at least one more operation than that appearing most frequently and are at least 3.5\% more expensive than the reference (optimal) product variant (highlighted in grey), they will never appear as an optimal solution (see product variants $1 \mathrm{C}$ and $1 \mathrm{~A}$; $2 \mathrm{~B}, 2 \mathrm{C}$, and $2 \mathrm{~A}$; $3 \mathrm{C}-3 \mathrm{~F}$ and $3 \mathrm{~A}$ ).

In summary, depending on the initial machines' configurations, different product variants will appear like the optimal solution, confirming the impact of the initial RMS configuration on the overall manufacturing costs as well as on the optimal product configuration and process plan. The product variants that appeared the most were those presenting the lowest raw-material cost and the fewest number of required operations.

Regarding the overall costs, the results suggest that when the raw material cost of different product configurations are slightly different and they require the same (or a close) number of operations, it is more opportune to apply the joint-optimization of product and process planning configuration in RMS than the separated one. Nevertheless, if the raw material costs between two product configurations are considerably different while their process plans are quite close (e.g., same number and type of operations), the separated-optimization method may be enough for cost minimization. That is because the costs of the process plan will probably not compensate for the high difference in raw material costs.

Further research is required to compare joint and separated optimization approaches when other responses of interest are considered (e.g., customer satisfaction index, completion time, etc.) because they can considerably affect the optimal results. Besides, considering other constraints such as machine availability, delivery time, could also impact the optimization result, and then, help to evidence which method (joint or separated one) performs better to optimize the attributed-based customization of modular product configuration and process planning in RMS for MC contexts.

Table 7 shows some statistics of the 120 runs for each group of functions. The results suggest that for all groups of functions considered, the total cost can vary up to about $30 \%$ depending on initial machines' configurations. The average cost for all groups was close to 140-145€. The minimal costs obtained by groups 1, 2, and 3 were $126.31 €, 122.49 €$, and 120.73€. These minimal costs correspond to the most frequently selected product variants, according to data from Table 6 .

Groups 1 and 2 attained the minimum cost when the machines started with the following configurations: $\mathrm{W}_{1} \mathrm{C}_{1}, \mathrm{~W}_{2} \mathrm{C}_{2}, \mathrm{~W}_{3} \mathrm{C}_{1}$, and $\mathrm{W}_{4} \mathrm{C}_{4}$. In contrast, Group 3 attained minimum cost when the initial ma-

Table 6. Product variant candidates for each group of selected functions and the frequency they appeared as an optimal solution within the 120 runs

\begin{tabular}{|c|c|c|c|c|c|c|}
\hline Group & Functions & ID & Product variants & $\begin{array}{c}\text { Frequency } \\
(\%)\end{array}$ & $\begin{array}{c}\mathrm{N}^{0} \text { of required } \\
\text { operations }\end{array}$ & $\begin{array}{c}\text { Raw materia } \\
\text { cost }(€)\end{array}$ \\
\hline \multirow{3}{*}{1} & \multirow{3}{*}{$F_{2}, F_{6}, F_{7}, F_{10}$} & $1 \mathrm{~A}$ & M12, M22, M32, M43 & 75 & 10 & 52,6 \\
\hline & & $1 \mathrm{~B}$ & $\mathrm{M} 12, \mathrm{M} 21, \mathrm{M} 32, \mathrm{M} 42$ & 25 & 10 & 55,76 \\
\hline & & $1 C$ & M12, M21, M32, M43 & 0 & 11 & 55,26 \\
\hline \multirow{3}{*}{2} & \multirow{3}{*}{$\mathrm{F}_{2}, \mathrm{~F}_{6}, \mathrm{~F}_{7}, \mathrm{~F}_{9}$} & $2 \mathrm{~A}$ & M12, M22, M32, M41 & 100 & 9 & 50,8 \\
\hline & & $2 \mathrm{~B}$ & M12, M21, M32, M41 & 0 & 10 & 53,46 \\
\hline & & $2 C$ & M12, M21, M32, M42 & 0 & 10 & 55,76 \\
\hline \multirow{6}{*}{3} & \multirow{6}{*}{$\mathrm{F}_{4}, \mathrm{~F}_{5}, \mathrm{~F}_{8}, \mathrm{~F}_{9}$} & $3 \mathrm{~A}$ & M12, M21, M31, M41 & 87.5 & 10 & 42,66 \\
\hline & & $3 B$ & M11, M21, M31, M41 & 12.5 & 11 & 42,66 \\
\hline & & $3 C$ & M11, M21, M31, M42 & 0 & 11 & 44,96 \\
\hline & & $3 \mathrm{D}$ & M12, M21, M31, M42 & 0 & 10 & 44,96 \\
\hline & & $3 E$ & M13, M21, M31, M41 & 0 & 11 & 44,16 \\
\hline & & $3 F$ & M13, M21, M31, M42 & 0 & 11 & 46,46 \\
\hline
\end{tabular}


Table 7. Summary of results obtained by each group of functions considering different initial machines' configurations

\begin{tabular}{|c|c|c|c|}
\hline Group & 1 & 2 & 3 \\
\hline Functions & $F_{2}, F_{6}, F_{7}, F_{10}$ & $F_{2}, F_{6}, F_{7}, F_{9}$ & $F_{4}, F_{5}, F_{8}, F_{9}$ \\
\hline Responses & Total Cost (€) & Total Cost $(€)$ & Total Cost $(€)$ \\
\hline Mean & 145.51 & 140.21 & 141 \\
\hline StDev & 7.49 & 8.07 & 8.67 \\
\hline Minimum & 126.31 & 122.49 & 120.73 \\
\hline Median & 144.58 & 139.95 & 141.62 \\
\hline Maximum & 164.52 & 159.49 & 159.28 \\
\hline Gap & $30.25 \%$ & $30.21 \%$ & $31.94 \%$ \\
\hline
\end{tabular}

a)

\section{Main Effects Plot for Total Cost_1}

Fitted Means

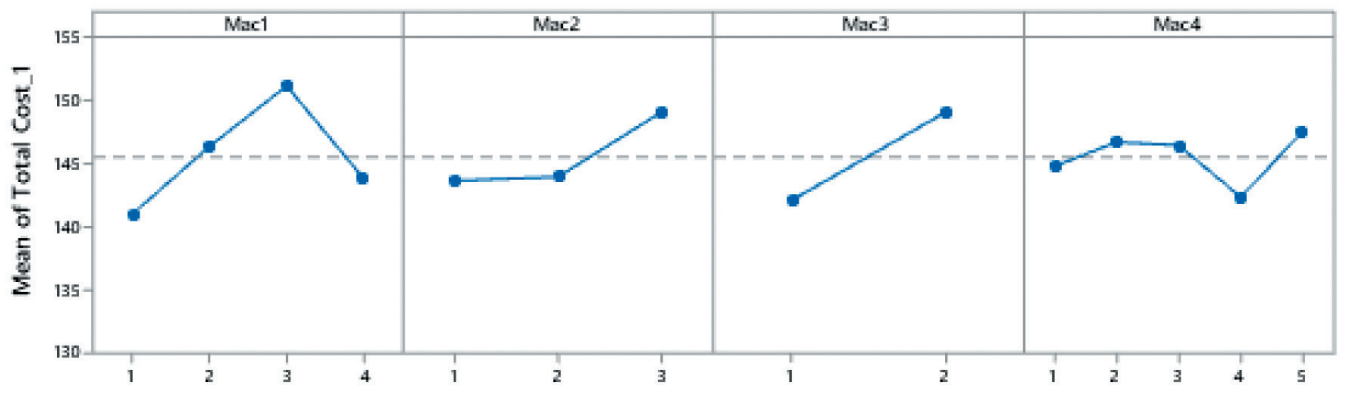

b)

Main Effects Plot for Total Cost_2

Fitted Means

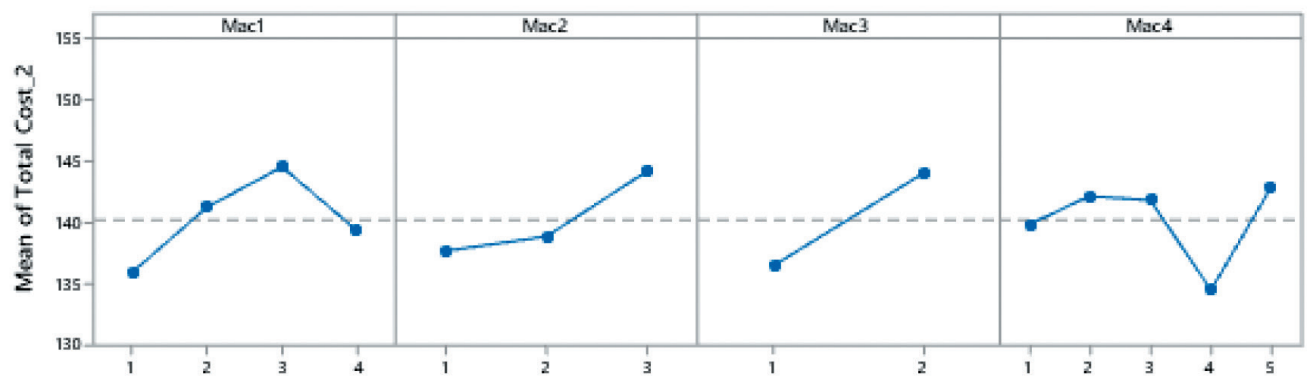

c)

Main Effects Plot for Total Cost_3

Fitted Means

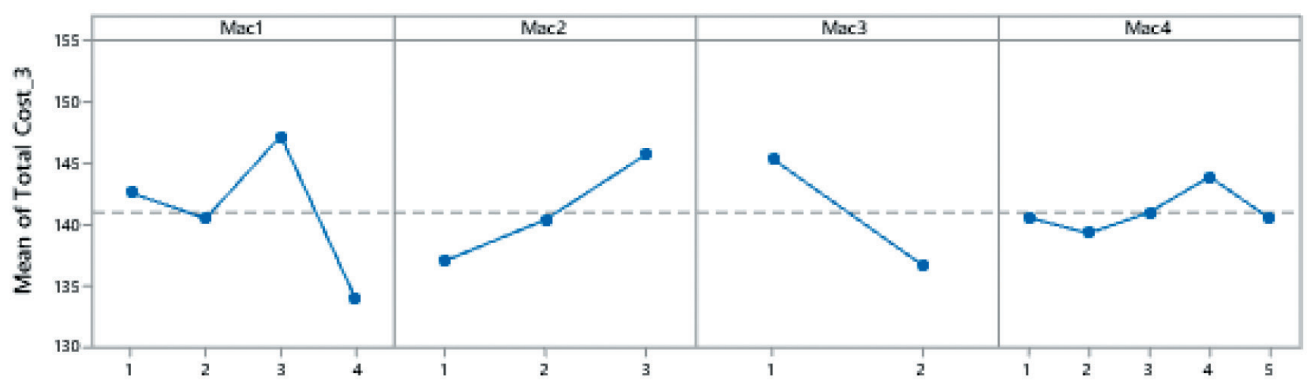

Figure 4. Main effects plot for the total cost of a) Group 1 b) Group 2, and c) Group 3

chines' configurations were $\mathrm{W}_{1} \mathrm{C}_{2}, \mathrm{~W}_{2} \mathrm{C}_{1}, \mathrm{~W}_{3} \mathrm{C}_{2}$, and $\mathrm{W}_{4} \mathrm{C}_{2}$, an initial configuration utterly different from the other two groups. The similar behavior between groups 1 and 2 is evidenced by the main effects plots of Figure 4a,b. They show that for groups 1 and 2 minimal total costs are obtained when machines $W_{1}$,
$\mathrm{W}_{2}, \mathrm{~W}_{3}, \mathrm{~W}_{4}$, respectively, start with the configurations $\mathrm{C}_{1}, \mathrm{C}_{1}, \mathrm{C}_{1}$, and $\mathrm{C}_{4}$. In contrast, for Group 3, the main effects plot (Figure 4c) suggests that minimal costs are obtained when the initial configuration of machines $\mathrm{W}_{1}, \mathrm{~W}_{2}, \mathrm{~W}_{3}, \mathrm{~W}_{4}$, are respectively, $\mathrm{C}_{4}, \mathrm{C}_{1}$, $\mathrm{C}_{2}, \mathrm{C}_{2}$. 
These results indicate a relationship between the type of product functions required and the preferable initial machines' configurations.

\section{Conclusion}

This paper proposed a 0-1 ILP model to jointly optimize the configuration of the attribute-based product customization and the process planning in RMS aiming at minimizing the overall manufacturing costs for MC. The total manufacturing costs include module instances' raw material, manufacturing and assembly operations, machine configuration change, and material handling related costs.

A hybrid deterministic solution approach based on an exhaustive search algorithm and CPLEX (ESA-CPLEX) was developed to test and validate the mathematical model proposed. The results evidenced the 0-1ILP model consistency and the ESACPLEX ability to solve this model in relatively low computation time for a small problem size. Further research is still required to test and compare the results from this paper with other solution approaches as well as with other types/sizes of problems.

The influence of initial machines' configurations as well as the type of functions (groups) required by the customer on the total manufacturing costs were investigated and results indicate a considerable influence of machines' initial configuration on the overall manufacturing costs (differences up to $30 \%$ ). Further, depending on the initial machines' configuration, different product variants appeared as the optimal solution for the same set of required functions. These results contribute to corroborating the impact of RMS's current configuration on manufacturing costs and the benefits of concurrently optimizing product configuration and process planning in an RMS for minimizing total manufacturing costs.

In summary, the results confirm the interest and applicability of the new attribute-based customization method based on the joint optimization of product configuration and process planning in RMS. The attribute-based approach proposed in this paper can guide the customers during their choice with a promising capacity to help them find out what they want, potentially reducing the paradox of choice during the customization process. Therefore, the approach proposed here can be potentially integrated into a configurator to optimize the offering of candidate product variants, as presented by Sabioni et al. [48].

One limitation of this work is that it only considers the cost as a response of interest and is limited to the product and process; with no reference to other supply chain aspects. However, as reported by Weber and Chatzopoulos [49], in MC contexts the customer experience, and then, their satisfaction, can be highly influenced by many other aspects related to the whole supply chain. Therefore, future researches can include other aspects in parallel to the cost, such as customer-perceived utility or delivery time, and can include other aspects from the supply chain, such as supplier selection and delivery option.

\section{Funding}

This research has been funded by the French National Agency of Research (Agence Nationale de la Recherche - ANR) as part of the project Integrated Product and Process Modular Design (IPROD).

\section{References}

[1] B. J. Pine, 'Mass customizing products and services', Planning Review, vol. 21, no. 4, pp. 6-55, 1993.

[2] M. M. Tseng, Y. Wang, and R. J.Jiao, 'Mass Customization', in The International Academy for Produ, Laperrière L., Reinhart G. (eds) CIRP Encyclopedia of Production Engineering, Berlin, Heidelberg: Springer, 2017.

[3] S. Davis, Future Perfect. Addison-Wesley Publishing, Reading, MA, 1987.

[4] B. J. Pine, Mass customization: The new frontier in business competition. Harvard Business School Press, 1993.

[5] E. Feitzinger and H. L. Lee, 'Mass Customization at Hewlett-Packard: The Power of Postponement.', Harvard Business Review, vol. 75, no. 1. pp. 116-121, 1997.

[6] J. Jiao and M. M. Tseng, 'Fundamentals of product family architecture', Integrated Manufacturing Systems, vol. 11, no. 7, pp. 469-483, 2000.

[7] C. Huffman and B. E. Kahn, 'Variety for sale: Mass customization or mass confusion?', Journal of Retailing, vol. 74, no. 4, pp. 491-513, Sep. 1998.

[8] N. Franke and F. T. Piller, 'Configuration Toolkits for Mass Customization Setting a Research Agenda', Innovation, vol. 33, no. 33, pp. 1-29, 2002.

[9] P. Pitiot, M. Aldanondo, E. Vareilles, P. Gaborit, M. Djefel, and S. Carbonnel, 'Concurrent product configuration and process planning, towards an approach combining interactivity and optimality', International Journal of Production Research, vol. 51, no. 2, pp. 524-541, 2013.

[10] P. Pitiot, M. Aldanondo, and E. Vareilles, 'Concurrent product configuration and process planning: Some optimization experimental results', Computers in Industry, vol. 65 , no. 4, pp. 610-621, 2014.

[11] Y. Koren, The Global Manufacturing Revolution: ProductProcess-Business Integration and Reconfigurable Systems. John Wiley \& Sons, Inc., 2010.

[12] A. Bryan, H. Wang, and J. Abell, 'Concurrent Design of Product Families and Reconfigurable Assembly Systems', Journal of Mechanical Design, vol. 135, no. May 2013, pp. $1-16,2017$.

[13] R. C. Sabioni, J. Daaboul, and J. Le Duigou, 'An integrated approach to optimize the configuration of mass-customized products and reconfigurable manufacturing systems', The International Journal of Advanced Manufacturing Technology, 2021. 
[14] F. A. Touzout and L. Benyoucef, 'Multi-objective multi-unit process plan generation in a reconfigurable manufacturing environment: a comparative study of three hybrid metaheuristics', International Journal of Production Research, vol. 57, no. 24, pp. 7520-7535, 2019.

[15] F. A. Touzout and L. Benyoucef, 'Multi-objective sustainable process plan generation in a reconfigurable manufacturing environment : exact and adapted evolutionary approaches', International Journal of Production Research, vol. 57, no. 8, pp. 2531-2547, 2019.

[16] A. Khezri, H. H. Benderbal, and L. Benyoucef, 'Towards a sustainable reconfigurable manufacturing system (SRMS): multi-objective based approaches for process plan generation problem', International Journal of Production Research, 2020.

[17] E. Massimi, A. Khezri, H. H. Benderbal, and L. Benyoucef, 'A heuristic-based non-linear mixed integer approach for optimizing modularity and integrability in a sustainable reconfigurable manufacturing environment', International Journal of Advanced Manufacturing Technology, vol. 108, no. 7-8, pp. 1997-2020, 2020.

[18] N. Suzić, E. Sandrin, S. Suzić, C. Forza, A. Trentin, and Z. Anišić, 'Implementation guidelines for mass customization: A researcher-oriented view', International Journal of Industrial Engineering and Management, vol. 9, no. 4, pp. 229-243, 2018, doi: 10.24867/IJIEM-2018-4-229

[19] N. Suzić, C. Forza, A. Trentin, and Z. Anišić, 'Implementation guidelines for mass customization: current characteristics and suggestions for improvement', Production Planning and Control, vol. 29, no. 10, pp. 856871, 2018.

[20] M. Rungtusanatham and C. Forza, 'Coordinating product design, process design, and supply chain design decisions: Part A: Topic motivation, performance implications, and article review process', Journal of Operations Management, vol. 23, no. 3-4, pp. 257-265, 2005.

[21] Y. Koren and M. Shpitalni, 'Design of reconfigurable manufacturing systems', Journal of Manufacturing Systems, vol. 29, no. 4, pp. 130-141, 2010.

[22] D. Yang and M. Dong, 'A hybrid approach for modeling and solving product configuration problems', Concurrent Engineering Research and Applications, vol. 20, no. 1, pp. 31-42, 2012.

[23] D. Yang, J. Li, B. Wang, and Y. J. Jia, 'Module-Based product configuration decisions considering both economical and carbon emission-related environmental factors', Sustainability (Switzerland), vol. 12, no. 3, pp. $1-13,2020$.

[24] W. B. Lee, H. Lau, Z. Liu, and S. Tam, 'A fuzzy analytic hierarchy process approach in modular', Expert Systems, vol. 18, no. 1, pp. 32-42, 2001.

[25] B. Li, L. Chen, Z. Huang, and Y. Zhong, 'Product configuration optimization using a multiobjective genetic algorithm, International Journal of Advanced Manufacturing Technology, vol. 30, no. 1-2, pp. 20-29, 2006.

[26] C. Da Cunha, B. Agard, and A. Kusiak, 'Design for Cost: Module-Based Mass Customization', IEEE Transactions on Automation Science and Engineering, vol. 4, no. 3, pp. 350-359, 2007.

[27] R. E. H. Khalaf, B. Agard, and B. Penz, 'An experimental study for the selection of modules and facilities in a mass customization context', Journal of Intelligent Manufacturing, vol. 21, no. 6, pp. 703-716, 2010.

[28] R. E. H. Khalaf, B. Agard, and B. Penz, 'Simultaneous design of a product family and its related supply chain using a Tabu Search algorithm', International Journal of Production Research, vol. 49, no. 19, pp. 5637-5656, 2011.
[29] A. Rezaei, M. Rahiminezhad Galankashi, S. Mansoorzadeh, and F. Mokhatab Rafiei, 'Supplier Selection and Order Allocation with Lean Manufacturing Criteria: An Integrated MCDM and Bi-objective Modelling Approach', EMJ Engineering Management Journal, vol. 32, no. 4, pp. 253271, 2020.

[30] M. R. Galankashi, N. Madadi, S. A. Helmi, A. R. A. Rahim, and F. M. Rafiei, 'A Multiobjective Aggregate Production Planning Model for Lean Manufacturing: Insights From Three Case Studies', IEEE Transactions on Engineering Management, pp. 1-15, 2020.

[31] P. Pitiot, L. G. Monge, M. Aldanondo, E. Vareilles, and P. Gaborit, 'Optimisation of the concurrent product and process configuration: an approach to reduce computation time with an experimental evaluation', International Journal of Production Research, vol. 58, no. 2, pp. 631-647, 2020.

[32] L. Wang, S. S. Zhong, and Y. J. Zhang, 'Process configuration based on generative constraint satisfaction problem', Journal of Intelligent Manufacturing, vol. 28, no. 4, pp. 945-957, Apr. 2017.

[33] R. E. H. Khalaf, B. Agard, and B. Penz, 'An experimental study for the selection of modules and facilities in a mass customization context', Journal of Intelligent Manufacturing, vol. 21, pp. 703-716, 2010.

[34] R. E. H. Khalaf, B. Agard, and B. Penz, 'Module Selection and Supply Chain Optimization for Customized Product Families Using Redundancy and Standardization', IEEE Transactions On Automation Science And Engineering, vol. 8, no. 1, pp. 118-129, 2011.

[35] L.-C. Chen and L. Lin, 'Optimization of product configuration design using functional requirements and constraints', Research in Engineering Design, vol. 13, pp. 167-182, 2002.

[36] H. Xie, P. Henderson, and M. Kernahan, 'Modelling and solving engineering product configuration problems by constraint satisfaction', International Journal of Production Research, vol. 43, no. 20, pp. 4455-4469, 2005.

[37] H. H. Benderbal and L. Benyoucef, 'Machine layout design problem under product family evolution in reconfigurable manufacturing environment: a two-phase-based AMOSA approach', International Journal of Advanced Manufacturing Technology, vol. 104, no. 1-4, pp. 375-389, 2019.

[38] M. R. Abdi and A. Labib, 'RMS capacity utilisation: product family and supply chain', International Journal of Production Research, vol. 55, no. 7, pp. 1930-1956, 2016.

[39] A. Bryan, J. Ko, and A. Arbor, 'Co-Evolution of Product Families and Assembly Systems', CIRP Annals Manufacturing Technology, vol. 56, no. 2, pp. 41-44, 2007.

[40] L. N. Pattanaik and A. Jena, 'Tri-objective optimisation of mixed model reconfigurable assembly system for modular products', International Journal of Computer Integrated Manufacturing, vol. 32, no. 1, pp. 72-82, 2018.

[41] R. C. Sabioni, J. Daaboul, J. Le Duigou, and J. Daaboul, 'Concurrent optimisation of modular product and Reconfigurable Manufacturing System configuration: a customer-oriented offer for mass customisation System configuration: a customer-oriented offer for mass customisation', International Journal of Production Research, 2021.

[42] Z. $\mathrm{Xu}$ and M. Liang, 'Integrated planning for product module selection and assembly line design/reconfiguration', International Journal of Production Research, vol. 44, no. 11, pp. 39-65, 2006.

[43] Z. Xu and M. Liang, 'Concurrent Optimization of Product Module Selection and Assembly Line Configuration: A Multi-Objective Approach', Journal of Manufacturing Science and Engineering, vol. 127, no. 4, pp. 875-884, 2005. 
[44] A. S. Yigit, A. G. Ulsoy, and A. Allahverdi, 'Optimizing modular product design for reconfigurable manufacturing', Journal of Intelligent Manufacturing, vol. 13, no. 4, pp. 309-316, 2002.

[45] A. S. Yigit and A. Allahverdi, 'Optimal selection of module instances for modular products in reconfigurable manufacturing systems', International Journal of Production Research, vol. 41, no. 17, pp. 4063-4074, 2003.

[46] K. K. Mittal, P. K. Jain, and D. Kumar, 'Optimal selection of modular products in reconfigurable manufacturing systems using analytic hierarchy process', International Journal of Logistics Systems and Management, vol. 30, no. 4, pp. 521-537, 2018.
[47] J. E. Mitchell, 'Integer Programming: Branch and Cut Algorithms', in Encyclopedia of Optimization, C. Floudas and P. Pardalos, Eds. Springer, Boston, MA, 2008, pp. $1549-1556$.

[48] R. Sabioni, L. Wartelle, J. Daaboul, and J. Le Duigou, 'Attribute-based integrated product process configurator for mass customization', Procedia CIRP, vol. 103, pp. 140$145,2021$.

[49] M. Weber and C. G. Chatzopoulos, 'Digital customer experience: The risk of ignoring the non-digital experience', International Journal of Industrial Engineering and Management, vol. 10, no. 3, pp. 201-210, 2019, doi: 10.24867/IJIEM-2019-3-240

\section{Appendix A}

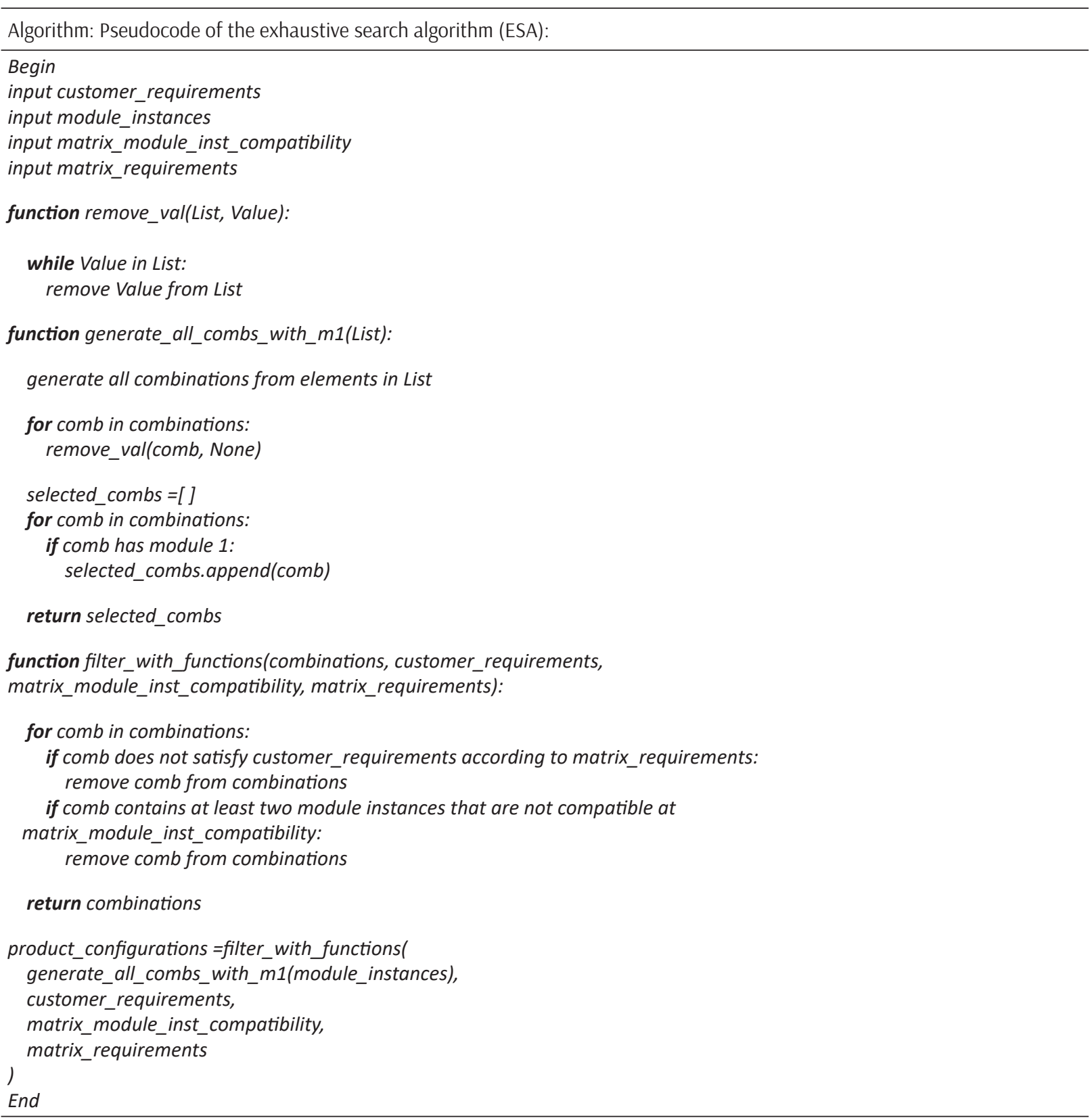




\section{Appendix B}

Table A1. Operation cost

\begin{tabular}{|c|c|c|c|c|c|c|c|c|c|c|c|c|c|c|}
\hline Operations & W1C1 & W1C2 & W1C3 & W1C4 & W2C1 & W2C2 & W2C3 & W3C1 & W3C2 & W4C1 & W4C2 & W4C3 & W4C4 & W4C5 \\
\hline 1 & 30 & 26,5 & & & & 33 & & & & & & & & \\
\hline 2 & & & 10 & & 15 & & & & 12,6 & & & & & \\
\hline 3 & & & & & & 12 & & & 14 & 16 & & & & \\
\hline 4 & & & 17,2 & & & & 19 & & & & & 16 & & \\
\hline 5 & 19 & & & & & & & 17 & & 23 & & & & \\
\hline 6 & & & & 17,5 & & 15 & & 12 & & & 14 & & & \\
\hline 7 & & 15 & & & 12 & & & & & & & & & \\
\hline 8 & & & & 13 & & & & & & 19 & 17,3 & & & \\
\hline 9 & & & & & & & & & 22,8 & & & 24,9 & & 34,6 \\
\hline 10 & 7 & & & 40 & 30 & & & & & 60 & 54,8 & & & \\
\hline 11 & & & & & & & & 7 & & & & & & \\
\hline 12 & & & & & & & 6 & 9,7 & & & & & & \\
\hline 13 & & & 23,4 & & & & 28,7 & & 31 & & & & & \\
\hline 14 & & & & & & & & & 7,64 & & & & 9,5 & \\
\hline 15 & & & & & & & & & 17,4 & & & & 18,2 & \\
\hline 16 & & & & & & & & 13 & & & & & & 18,9 \\
\hline
\end{tabular}

Table A2. Operation time

\begin{tabular}{|c|c|c|c|c|c|c|c|c|c|c|c|c|c|c|}
\hline Operations & W1C1 & W1C2 & W1C3 & W1C4 & W2C1 & W2C2 & W2C3 & W3C1 & W3C2 & W4C1 & W4C2 & W4C3 & W4C4 & W4C5 \\
\hline 1 & 0,05 & 0,04 & & & & 0,07 & & & & & & & & \\
\hline 2 & & & 0,02 & & 0,09 & & & & 0,14 & & & & & \\
\hline 3 & & & & & & 0,04 & & & 0,07 & 0,11 & & & & \\
\hline 4 & & & 0,04 & & & & 0,16 & & & & & 0,11 & & \\
\hline 5 & 0,05 & & & & & & & 0,12 & & 0,05 & & & & \\
\hline 6 & & & & 0,07 & & 0,09 & & 0,04 & & & 0,07 & & & \\
\hline 7 & & 0,09 & & & 0,04 & & & & & & & & & \\
\hline 8 & & & & 0,05 & & & & & & 0,16 & 0,12 & & & \\
\hline 9 & & & & & & & & & 0,10 & & & 0,07 & & 0,05 \\
\hline 10 & 0,12 & & & 0,07 & 0,05 & & & & & 0,11 & 0,16 & & & \\
\hline 11 & & & & & & & & 1,10 & & & & & & \\
\hline 12 & & & & & & & 0,98 & 0,89 & & & & & & \\
\hline 13 & & & 0,05 & & & & 0,02 & & 0,08 & & & & & \\
\hline 14 & & & & & & & & & 0,71 & & & & 0,35 & \\
\hline 15 & & & & & & & & & 0,35 & & & & 0,18 & \\
\hline 16 & & & & & & & & 0,50 & & & & & & 0,20 \\
\hline
\end{tabular}

Table A7. Configuration change cost

\begin{tabular}{|c|c|c|c|c|c|c|c|c|c|c|c|c|c|c|}
\hline Machines & W1C1 & W1C2 & W1C3 & W1C4 & W2C1 & W2C2 & W2C3 & W3C1 & W3C2 & W4C1 & W4C2 & W4C3 & W4C4 & W4C5 \\
\hline W1C1 & 0 & 0,7 & 0,8 & 1,3 & & & & & & & & & & \\
\hline W1C2 & 0,8 & 0 & 1,2 & 0,9 & & & & & & & & & & \\
\hline W1C3 & 0,6 & 1,3 & 0 & 0,7 & & & & & & & & & & \\
\hline W1C4 & 1,1 & 0,8 & 1 & 0 & & & & & & & & & & \\
\hline W2C1 & & & & & 0 & 0,9 & 1,1 & & & & & & & \\
\hline W2C2 & & & & & 1 & 0 & 0,6 & & & & & & & \\
\hline W2C3 & & & & & 0,7 & 0,4 & 0 & & & & & & & \\
\hline W3C1 & & & & & & & & 0 & 1,4 & & & & & \\
\hline W3C2 & & & & & & & & 1,1 & 0 & & & & & \\
\hline W4C1 & & & & & & & & & & 0 & 0,5 & 0,7 & 1,1 & 0,38 \\
\hline W4C2 & & & & & & & & & & 1,3 & 0 & 0,3 & 1,4 & 0,486 \\
\hline W4C3 & & & & & & & & & & 0,8 & 1,2 & 0 & 0,85 & 0,71 \\
\hline W4C4 & & & & & & & & & & 0,9 & 1 & 0,92 & 0 & 0,923 \\
\hline W4C5 & & & & & & & & & & 0,378 & 0,7 & 0,6 & 1,36 & 0 \\
\hline
\end{tabular}


Table A8. Configuration change time

\begin{tabular}{|c|c|c|c|c|c|c|c|c|c|c|c|c|c|c|}
\hline Machines & W1C1 & W1C2 & W1C3 & W1C4 & W2C1 & W2C2 & W2C3 & W3C1 & W3C2 & W4C1 & W4C2 & W4C3 & W4C4 & W4C5 \\
\hline W1C1 & 0 & 29 & 21 & 3 & & & & & & & & & & \\
\hline W1C2 & 7 & 0 & 10 & 28 & & & & & & & & & & \\
\hline W1C3 & 20 & 29 & 0 & 15 & & & & & & & & & & \\
\hline W1C4 & 18 & 15 & 18 & 0 & & & & & & & & & & \\
\hline W2C1 & & & & & 0 & 23 & 23 & & & & & & & \\
\hline W2C2 & & & & & 11 & 0 & 9 & & & & & & & \\
\hline W2C3 & & & & & 22 & 11 & 0 & & & & & & & \\
\hline W3C1 & & & & & & & & 0 & 13 & & & & & \\
\hline W3C2 & & & & & & & & 13 & 0 & & & & & \\
\hline W4C1 & & & & & & & & & & 0 & 24 & 6 & 22 & 29 \\
\hline W4C2 & & & & & & & & & & 19 & 0 & 20 & 30 & 17 \\
\hline W4C3 & & & & & & & & & & 4 & 10 & 0 & 5 & 31 \\
\hline W4C4 & & & & & & & & & & 14 & 10 & 25 & 0 & 18 \\
\hline W4C5 & & & & & & & & & & 28 & 14 & 27 & 13 & 0 \\
\hline
\end{tabular}

Table A9. Operation precedence matrix

\begin{tabular}{|c|c|c|c|c|c|c|c|c|c|c|c|c|c|c|c|c|}
\hline Operation & $\mathbf{1}$ & $\mathbf{2}$ & $\mathbf{3}$ & $\mathbf{4}$ & $\mathbf{5}$ & $\mathbf{6}$ & $\mathbf{7}$ & $\mathbf{8}$ & $\mathbf{9}$ & $\mathbf{1 0}$ & $\mathbf{1 1}$ & $\mathbf{1 2}$ & $\mathbf{1 3}$ & $\mathbf{1 4}$ & $\mathbf{1 5}$ & $\mathbf{1 6}$ \\
\hline $\mathbf{1}$ & 0 & 0 & 0 & 0 & 0 & 0 & 0 & 0 & 0 & 0 & 0 & 0 & 0 & 0 & 0 & 0 \\
\hline $\mathbf{2}$ & 1 & 0 & 0 & 0 & 0 & 0 & 0 & 0 & 0 & 0 & 0 & 0 & 0 & 0 & 0 & 0 \\
\hline $\mathbf{3}$ & 1 & 1 & 0 & 0 & 0 & 0 & 0 & 0 & 0 & 0 & 0 & 0 & 0 & 0 & 0 & 0 \\
\hline $\mathbf{4}$ & 1 & 1 & 0 & 0 & 0 & 0 & 0 & 0 & 0 & 0 & 0 & 0 & 0 & 0 & 0 & 0 \\
\hline $\mathbf{5}$ & 0 & 1 & 1 & 1 & 0 & 0 & 0 & 0 & 0 & 0 & 0 & 0 & 0 & 0 & 0 & 0 \\
\hline $\mathbf{6}$ & 1 & 0 & 1 & 1 & 1 & 0 & 0 & 0 & 0 & 0 & 0 & 0 & 0 & 0 & 0 & 0 \\
\hline $\mathbf{7}$ & 1 & 0 & 1 & 1 & 1 & 0 & 0 & 1 & 0 & 0 & 0 & 0 & 0 & 0 & 0 & 0 \\
\hline $\mathbf{8}$ & 1 & 0 & 1 & 1 & 0 & 1 & 0 & 0 & 0 & 0 & 0 & 0 & 0 & 0 & 0 & 0 \\
\hline $\mathbf{9}$ & 1 & 1 & 0 & 1 & 1 & 0 & 1 & 1 & 0 & 0 & 0 & 0 & 0 & 0 & 0 & 0 \\
\hline $\mathbf{1 0}$ & 1 & 1 & 1 & 0 & 1 & 0 & 1 & 0 & 0 & 0 & 0 & 0 & 0 & 0 & 0 & 0 \\
\hline $\mathbf{1 1}$ & 1 & 1 & 1 & 1 & 1 & 1 & 1 & 1 & 1 & 1 & 0 & 0 & 0 & 0 & 0 & 0 \\
\hline $\mathbf{1 2}$ & 1 & 1 & 1 & 1 & 1 & 1 & 1 & 1 & 1 & 1 & 0 & 0 & 0 & 0 & 0 & 0 \\
\hline $\mathbf{1 3}$ & 1 & 1 & 1 & 1 & 1 & 1 & 1 & 1 & 1 & 1 & 0 & 0 & 0 & 0 & 0 & 0 \\
\hline $\mathbf{1 4}$ & 1 & 1 & 1 & 1 & 1 & 1 & 1 & 1 & 1 & 1 & 0 & 0 & 0 & 0 & 0 & 0 \\
\hline $\mathbf{1 5}$ & 1 & 1 & 1 & 1 & 1 & 1 & 1 & 1 & 1 & 1 & 0 & 0 & 0 & 0 & 0 & 0 \\
\hline $\mathbf{1 6}$ & 1 & 1 & 1 & 1 & 1 & 1 & 1 & 1 & 1 & 1 & 0 & 0 & 0 & 0 & 0 & 0 \\
\hline
\end{tabular}

